\title{
Twenty years of home-based palliative care in Malappuram, Kerala, India: a descriptive study of patients and their care-givers
}

\author{
Rekha Rachel Philip ${ }^{1 *}$, Sairu Philip', Jaya Prasad Tripathy ${ }^{2}$, Abdulla Manima ${ }^{3}$ and Emilie Venables ${ }^{4,5}$
}

\begin{abstract}
Background: The well lauded community-based palliative care programme of Kerala, India provides medical and social support, through home-based care, for patients with terminal illness and diseases requiring long-term support. There is, however, limited information on patient characteristics, caregivers and programme performance. This study was carried out to describe: i) the patients enrolled in the programme from 1996 to 2016 and their diagnosis, and ii) the care-giver characteristics and palliative care support from nurses and doctors in a cohort of patients registered during 2013-2015.
\end{abstract}

Methods: A descriptive study was conducted in the oldest community-based palliative clinic in Kerala. Data were collected from annual patient registers from 1996 to 2016 and patient case records during the period 2013-2015.

Results: While 91\% of the patients registered in the clinic in 1996 had cancer, its relative proportion came down to 32\% in 2016 with the inclusion of dementia-related illness (19\%) cardiovascular accidents (17\%) and severe mental illness (5\%).Among patients registered during 2013-15, the median number of home visits from nurses and doctors in 12 months were five and one respectively. In the same cohort, twelve months' post-enrolment, 56\% of patients died, $30 \%$ were in continuing in active care and $7 \%$ opted out. Those who opted out of care were likely to be aged $<60$ years, received one or less visit annually from a doctor or have a serious mental illness. $96 \%$ of patients had a care-giver at home, $85 \%$ of these care-givers being female.

Conclusions: The changing dynamics over a 20-year period of this palliative care programme in Kerala, India, highlights the need for similar programmes to remain flexible and adapt their services in response to a growing global burden of Non Communicable Diseases. While a high death rate is expected in this population, the high proportion of patients choosing to stay in the programme suggests that home-based care is valued within this particular group. A diverse range of clinical and psycho-social support skills are required to assist families and their caregivers when caring for a cohort such as this one.

Keywords: Home-based care, Palliative care, Community-based care, Care-givers, Chronic disease, Cancer

\section{Background}

Palliative care is gaining significance due to a global increase in the prevalence of Non-Communicable Diseases (NCDs) and the consequent increase in the numbers of patients requiring long-term care for chronic conditions [1]. In spite of the existence of palliative care

\footnotetext{
* Correspondence: rekharachel@gmail.com

${ }^{1}$ Department of Community Medicine, Government T.D Medical College,

Alappuzha, Kerala, India

Full list of author information is available at the end of the article
}

services in more than half of the world's countries, there is a need for major expansion for its global accessibility [2].

The South Asian Region which homes one quarter of the world's population has 1.33 million new cancer cases every year, of which majority present in the later stages of their disease. This is in addition to the burden of other chronic diseases such as end-stage heart failure, cerebrovascular accidents, renal and respiratory diseases which require specialized palliative care [3-6]. Despite this increase in the chronic disease burden, palliative care provision exists in very few countries in the region [7]. 
Palliative care has been reported to be cost-effective compared to conventional hospital-based and episodic medical care in providing symptomatic relief and improving quality of life [8]. Palliative care is currently provided as home based care or as acute care in hospital setting or as institutional aged care settings sometimes referred to as hospice care [9]. A systematic review by Finlay et al. demonstrated the effectiveness of palliative care, especially home based care over hospital based care with a definite advantage of multi-disciplinary team approach [10]. Home based palliative care involves doorstep provision of holistic care usually by a multidisciplinary team [11]. Home based palliative care existent in European countries provide different models of care, reflecting complexity and context diversity [12].

In United Kingdom, care homes are important providers of palliative care for older people where care is provided by multiple health care service providers who provide care and treatment for residents in care homes [13]. The home care team of specialist palliative care services in Scotland consists of clinicians and nurses who are jointly appointed to work between the independent hospices, the acute hospital sector and community services to provide integrated care [14].

In United States palliative care services are well established within hospitals and hospice care. Hospital palliative care teams focus on caring for seriously ill patients. However, newer models of palliative care delivering services to patients living in the community have been tried recently. Here, interdisciplinary home care is provided through certified home health agencies or hospices outside the Medicare Hospice Benefit whereas hospital-based teams provide physician home visits [15].

Home-based models of palliative care provide homebased care and support for family-care givers as well. It avoids futile treatments and optimizes use of specialist palliative care expertise. Palliative care adopted in the acute care sector largely consists of specialist consultative services, inpatient palliative units/beds or nurse practitioner models $[16,17]$. There has also been an expansion of the traditional focus on specialist palliative care teams caring for people with cancer to include a wide range of life limiting diseases $[18,19]$. Thus, an ever increasing need to establish appropriate, locally relevant, feasible and effective palliative care for all, irrespective of diagnosis, place of care or geographical region is the current challenge [20].

The various models of palliative care service in India include inpatient care (in hospices or hospitals); outpatient clinics (in hospitals and other settings); and home care services (run by hospitals, hospices or volunteer networks) [21]. The state of Kerala harbours $90 \%$ of the country's palliative care programmes though it has only $3 \%$ of the country's population. This is characterized by a large number of home care services, which have wider coverage [22]. This home-based provision relies on the strength of family support and the enthusiasm of the volunteers. Informal care by family members is unique to this region compared to the developed world where care giving is usually in the form of paid formal care. [23, 24]. Most families prefer to care for the ill person throughout their illness. Most of the literature on feasibility and acceptability of palliative care in India has been based on the models in Kerala [25]. The home-based care services ensure continuity of care for patients and empower the caregiver in the family by teaching them simple and cost effective methods of caring for the patients. This is important in resource poor settings where access to institutional care is difficult [26].

Kerala pioneered community-based palliative care through a socially innovative approach called the Neighbourhood Network in Palliative Care in an attempt to develop a free of charge, sustainable, community led, service capable of offering comprehensive long-term care and palliative care. The network aimed to empower local communities to look after their chronically ill and dying patients. Funds for running the programme were raised locally by volunteers.

The programme was first piloted in 1996 in Malappuram, a northern district of Kerala, for patients with cancer which was then gradually expanded to include other conditions requiring long-term care such as cerebro-vascular accidents, dementia, paraplegia and psychiatric illness [27]. Volunteers from the local community were trained to identify the psycho-social problems of people with chronic conditions in their area and to intervene effectively with active support from a network of trained professionals [27]. The model was shown to be successful, and inspired the state to implement a palliative care policy to ensure universal coverage of palliative care services in all its local administrative units ( 1000 in numbers), making it the first state in Asia to develop such a policy [28]. The Policy considers home based care as the corner stone of palliative care services. The Neighbourhood Network in Palliative Care in Kerala as discussed above, has been described as an exemplar model of community-based palliative care for other low-resource countries world- wide [21].

Although various provisions of Kerala model of homebased palliative care have been described, there is limited information on patient characteristics and utilization of palliative care [25]. Earlier studies have reported that around $12-28 \%$ of patients chose to opt out of palliative care for various reasons which increases with a decrease in social support from the clinic and the number of home visits by the physician $[29,30]$. Understanding the patient characteristics, utilization of home-based palliative care and its predictors can assist service planners in the appropriate allocation of resources and service 
packaging to meet the complex needs of palliative care patients [24, 30].

Manjeri Pain and Palliative Care Clinic is the oldest community based palliative care clinic in Kerala, and understanding its evolution from 1996 to present may be useful in giving insights about patients and caregivers.

\section{Objectives}

The present study was carried out to: i) describe the demographic characteristics of patients enrolled in the programme from 1996 to 2016 and their diagnosis, ii) describe the professional palliative care support they received and the 12-month care outcomes (in active care/opted out of care/transferred out/died) among patients registered between 2013 and 2015, and iii) determine the factors associated with opting out of palliative care.

\section{Methods}

\section{Study design}

A descriptive study was conducted analyzing data from annual patient registers between 1996 and 2016 at Manjeri Palliative Care Clinic. For the second and third objectives, analysis of secondary data from patient case records among those registered between July 2013 and June 2015 was carried out. Outcome of only two years was taken because the documentation of patient case records became systematic only after 2013 .

\section{Setting}

The study was conducted in the town of Manjeri, Kerala, a state in the southernmost part of India. The state of Kerala enjoys the highest literacy rate, highest life expectancy and the highest sex ratio in India [31]. The town is located in the most populous district of Kerala (i.e. Malappuram) which has the lowest Human Development Index of 0.75 in the state, which has an overall index of 0.77 [32].

The first community based palliative care project of Malappuram district was in Manjeri. [33] Based on this model and the Kerala State Palliative care policy, the Panchayats/Municipalities (also known as county) in the district of Malappuram currently has two community based palliative care units, one run by the Community Based Organisations (CBOs) and one run by the Local Self Government Institutions (LSGIs). This study focused on the palliative care services provided by CBOs, which offered home-based care service to patients with a variety of long term illnesses through pain and palliative care clinics run by a team of doctors, nurses and volunteers. Nurses visit patients who require support in their homes, including catheterisation, nasogastric intubation, wound care and counseling support. Home visit by doctors is restricted to those patients who require a doctors' consultation, as charted by a nurse. Volunteers also visit patients and their families to provide a range of support including emotional and financial [33].

\section{Study population}

The study population comprised of all patients who were newly registered in the unit between January 1st 1996 and 31st December 2016. To assess the palliative care outcomes, we looked at patients newly registered in the unit between July 2013 and June 2015.

\section{Outcome variables and data sources}

The key outcome variable was patient's continuity/retention in the palliative care programme after one year of their enrolment in the clinic which was expressed as "in active care" where the patient was alive and still receiving home based palliative care from the same unit. Transferred out was defined as relocation to another care facility. Opted out of care was defined as the patient's decision to stop receiving care from the programme.

Sources of data were annual patient registers and patient case records at the Manjeri Pain and Palliative Care Clinic, Kerala. The annual registers contain the name, age and diagnosis of the patient and these have remained uniform over the last two decades. The patient case records contain baseline as well as follow-up information of the patients registered and are maintained by the caring nurses. These case records have been revised from time to time since 1996 and the latest revision was in 2013 whereby documentation became uniform and systematic.

Other operational definitions: The clinic classified the patients into four categories: Very poor, poor, middle and wealthy based on their household characteristics and ability to purchase healthcare. Very Poor-no earning member in the family; Poor-earning member present, but need support for medicines; Middle class-no support needed for daily living but partial financial assistance is needed for medicines; Wealthy-they don't need external financial help for supporting healthcare. They receive nursing care from the clinic but drugs are not provided free of cost.

For the purpose of this study, very poor, poor and middle class were clubbed into one category i.e. poor because they had limited means to support their treatment/medicines.

\section{Statistical analysis}

Data were entered using EpiData (version 3.1 for entry) and analyzed using EpiData analysis version 2.2.2.182 (EpiData Association, Odense, Denmark) and STATA Version 12. To ensure data quality, double data entry and validation was done. Categorical variables such as socio-demographic and 
clinical characteristics and care outcomes were summarized as proportions. To summarise continuous variables including the number of visits, median with Interquartile Range (IQR) was used. Chi square test was done to assess the associations of socio-economic and clinical variables with opting out of care. The strength of association was expressed using relative risk (RR) with 95\% Confidence Intervals. All factors with a $p$ value $<0.2$ in unadjusted analysis were put in a $\log$ binomial regression model to find out the independent predictors of "opting out of care" using STATA version 12 .

\section{Results}

A total of 5614 new patients were registered in the Manjeri Palliative Care Unit over a 20 year period (1996-2016). The demographic and clinical characteristics are shown in Table 1. Sixty-three percent of the newly registered patients were elderly ( $>60$ years), with only $1 \%$ aged 15 years or under. The most common primary diagnosis at enrolment

Table 1 Demographic and clinical characteristics of newly registered patients in the Manjeri Palliative Care Unit, Kerala, India during 1996-2016

\begin{tabular}{lll}
\hline Characteristics & Number & $(\%)$ \\
\hline Total & 5614 & $(100)$ \\
Age & & \\
$\quad<15$ years & 62 & $(1)$ \\
15-44 years & 681 & $(12)$ \\
$45-59$ years & 1321 & $(24)$ \\
60-79 years & 2443 & $(44)$ \\
$\geq 80$ years & 777 & $(14)$ \\
Missing & 330 & $(6)$ \\
Sex & & \\
Male & 3206 & $(57)$ \\
Female & 2396 & $(43)$ \\
Missing & 12 & $(<1)$ \\
Disease & & \\
Cancer & 3445 & $(61)$ \\
Cerebrovascular accident & 612 & $(11)$ \\
Dementia related & 419 & $(6)$ \\
Diabetes Mellitus & 125 & $(2)$ \\
Chronic kidney disease & 114 & $(2)$ \\
Peripheral vascular disease & 112 \\
Coronary heart disease & 106 \\
Fracture & 762 \\
Serious Mental illness & 201 \\
Paraplegia/Quadriplegia & & $(2)$ \\
Missing & 762 \\
\hline
\end{tabular}

into the palliative care unit was cancer (61\%). There were more men than women enrolled in the programme $(57 \%$ and $43 \%$ respectively). (Table 1 ).

The number of new patients enrolled annually from 1996 to 2016 is shown in Fig. 1. A rapid increase in the number of patients with CVAs, dementia related conditions, diabetes and serious mental illness is seen up until 2000, when a decline in enrolments is observed thereafter. The diagnosis of patients over these two decades is shown in Fig. 2. While cancer remains the major cause for enrolment, the proportion of patients enrolled due to cerebrovascular accidents (CVA), chronic kidney disease, severe mental illness and dementia related disorders has increased.

Almost all patients enrolled in the programme between 2013 and 2015 (96\%) had a care-giver (Table 2). Most of the caregivers (85\%) were women. The majority of care-givers $(84 \%)$ were relatives, with almost one third (31\%) being the spouse of the patient. After 12 months in the programme, over half $(56 \%)$ of the patients enrolled between 2013 and 2015 had died. Just under one third (30\%) were still in active care, with $7 \%$ having opted out, or chosen to discontinue, in the programme.

Nurses provided more home visits than doctors, with patients receiving a median of one visit from a doctor and five visits from a nurse in the 12 months following their enrolment in the programme. (Table 2).

The factors significantly associated with opting out of palliative care in unadjusted analysis were patients with age $\leq 60$ years, serious mental illness, one or less home visits from doctors and five or less home visits from nurses in their first 12 months of enrolment in the programme. Those patients with CVA were significantly less likely to opt out of care. After log binomial regression, the independent predictors of opting out of care were age $\leq 60$ years, having a serious mental illness and receiving one or less visit from doctors. Patients with CVA remained significantly less likely to opt out of care. (Table 3).

\section{Discussion}

A differing pattern in enrolment of patients into the home care programme was seen from 1996 to 2016. Although cancer remains the most common diagnosis, an increasing proportion of CVAs, dementia related conditions, diabetes and serious mental illness was seen when compared to the initial years of the programme.

Globally, cancer is one of the predominant conditions for which palliative care is offered [2]. A study conducted in Brazil revealed that amongst patients with palliative care needs, non-malignant diseases such as dementia and cerebrovascular diseases were the most common [34]. Cancer formed the predominant group in our study. This was consistent with a report from a similar setting in 


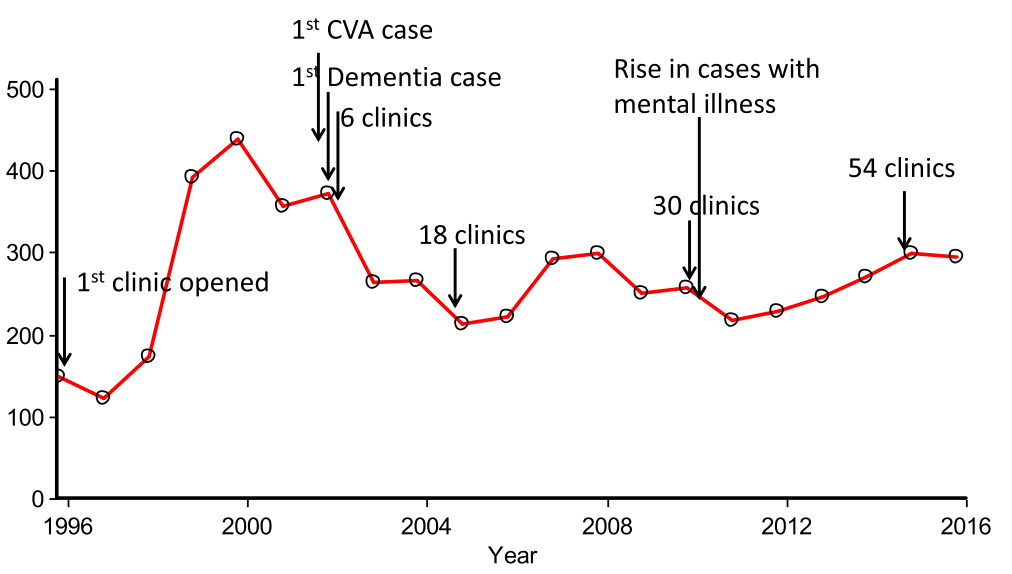

Fig. 1 Number of newly registered patients enrolled in the Manjeri Palliative Care Unit, Kerala, India during 1996-2016

Kerala where $50 \%$ beneficiaries of its home based palliative care were cancer patients [35]. Most of the palliative care services in other parts of the country cater to cancer patients $[21,25]$. We observed an increasing proportion of other illness in our study as years progressed which is mainly due to demographic transition fuelling a rapid rise in NCDs and other illnesses related to ageing, meaning that patients requiring care for chronic conditions are no longer only those with cancers [36]. The diversity of patient diagnoses suggests that many people, such as those who are paraplegic or suffering from mental illness, may require medical and psycho-social support for longer periods.

The initial rise in the number of patients registering at the clinic can be linked to the fact that at the time it was the only facility in the area providing palliative care, and it provided for patients not only from the study district

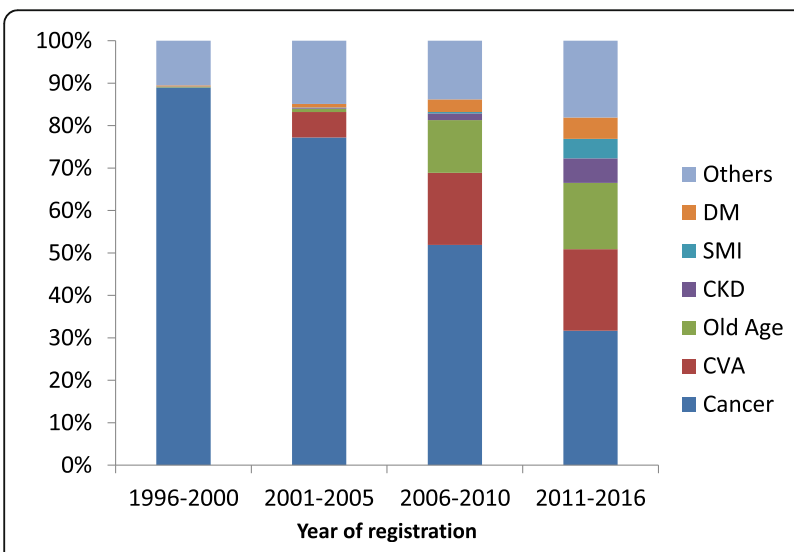

Fig. 2 Clinical diagnosis of newly registered patients in the Manjeri Palliative Care Unit, Kerala, India, 1996-2016. CVA = Cerebrovascular Accident; $C K D=$ Chronic Kidney Disease; $D M=$ Diabetes Mellitus; SMI=Serious mental illness; Other category includes Peripheral Occlusive Vascular Disease, Paraplegia, Hypertension, Fractures, Coronary Artery Disease of Malappuram but also from adjacent districts. This wide catchment area explains the rise in the number of patients up until 2000, whereas the decline that is observed thereafter is due to the establishment of five other clinics in the district from 2001. This decreasing number of patients with the coming up of new clinics is reported from a similar setting in Kerala (30). By 2008 there were 29 such clinics providing palliative care services. This decline was probably halted by the surge in admissions due to other chronic illness as described above. Other palliative care clinics opened during the 20 year study period, which may also explain some of the changes in enrolment rates.

Not surprisingly, the elderly patients were the predominant beneficiaries of the programme. [29, 35] In the cultural context of Kerala and India, family is the most vital non-formal social security and the most preferred living arrangement. National policy for the elderly upholds the concept of home care services for the aged and outlines institutional care as the last resort [37]. There are very few residential aged care arrangements in the district of Malappuram and this highlights the importance of home based palliative care services for the elderly. The palliative care policy of the state is also in line with the appropriateness of home based service in this context [28].

The majority of the care-givers were females, and were mostly the spouses or daughters-in-law of patients. The predominant number of female care-givers (particularly spouses and daughters-in-law) is also unsurprising in this context, where women traditionally take on the majority of household tasks, and these figures reflect the traditional gender roles within Kerala as a society. This gendered division of care-giving and informal, unpaid labour also exists in many other contexts, where women are sole providers of unskilled and unwaged care for family members with chronic medical conditions or disabilities, including the elderly and those with serious mental illnesses [38-40]. 
Table 2 Socio-demographic and clinical characteristics, 12-month care outcomes and palliative care support of patients registered in the Manjeri Palliative Care Unit, Kerala, India, 2013-2015

\begin{tabular}{|c|c|c|c|}
\hline \multicolumn{2}{|l|}{ Characteristics } & \multirow{2}{*}{$\frac{N}{551}$} & \multirow{2}{*}{$\frac{(\%)}{(100)}$} \\
\hline $\begin{array}{l}\text { Total } \\
\end{array}$ & & & \\
\hline \multirow[t]{5}{*}{ Age } & $<15$ years & 2 & $(<1)$ \\
\hline & $15-44$ years & 59 & (11) \\
\hline & $45-59$ years & 82 & (15) \\
\hline & $60-79$ years & 233 & $(42)$ \\
\hline & $\geq 80$ years & 175 & (32) \\
\hline \multirow[t]{3}{*}{ Sex } & Male & 265 & (48) \\
\hline & Female & 280 & (51) \\
\hline & Missing & 6 & (1) \\
\hline \multirow[t]{7}{*}{ Primary diagnosis } & Cancer & 151 & (27) \\
\hline & Cardiovascular accident & 123 & (22) \\
\hline & Dementia related & 59 & (11) \\
\hline & Serious Mental Illness & 33 & (6) \\
\hline & Fracture & 45 & (8) \\
\hline & Chronic kidney disease & 34 & (7) \\
\hline & Other & 106 & (19) \\
\hline \multirow[t]{8}{*}{ Secondary diagnosis } & Dementia related diseases & 35 & (6) \\
\hline & Fracture & 18 & (3) \\
\hline & Coronary artery disease & 17 & (3) \\
\hline & Serious Mental Illness & 9 & (2) \\
\hline & Seizure disorder & 9 & (2) \\
\hline & Metabolic Encephalopathy & 8 & (1) \\
\hline & Others & 8 & (1) \\
\hline & None & 447 & (81) \\
\hline \multirow[t]{4}{*}{ 12-month care outcome ${ }^{\mathrm{a}}$} & Died & 309 & (56) \\
\hline & In active care & 164 & (30) \\
\hline & Transferred out of care & 38 & (7) \\
\hline & Opted out of care & 40 & (7) \\
\hline \multirow[t]{4}{*}{ Care-giver status } & Care-giver present & 530 & (96) \\
\hline & Care-giver not required & 11 & (2) \\
\hline & Living alone & 5 & (1) \\
\hline & Missing & 5 & (1) \\
\hline \multirow[t]{8}{*}{ Type of care-giver } & Spouse & 171 & (31) \\
\hline & Daughter in law & 139 & (25) \\
\hline & Son/Daughter & 107 & (20) \\
\hline & Mother/Father & 32 & (6) \\
\hline & Hired care-giver & 11 & (2) \\
\hline & Sister-in-law & 13 & (2) \\
\hline & Other & 73 & (13) \\
\hline & Missing & 5 & (1) \\
\hline \multicolumn{4}{|c|}{$\begin{array}{l}\text { Median (IQR) number of home visits made by professional care } \\
\text { providers } 12 \text { months after patient enrollment in the programme }\end{array}$} \\
\hline \multicolumn{2}{|l|}{ Doctors } & 1 & $(1-2)$ \\
\hline \multicolumn{2}{|l|}{ Nurses } & 5 & $(2-9)$ \\
\hline
\end{tabular}

Being a care-giver entails a huge emotional, physical and social burden alongside the physical demands of routine household chores [41]. The stresses placed on care-givers suggest the need for structured palliative care programmes supported by nurses and physicians, that offer psychosocial support to the families of patients in addition to medical care.

A year after enrolment into the programme more than half of the patients died but among those who did not die, most preferred to continue receiving care in the home-based programme. The overall high death rate in our study suggests that palliative care still has an important role to play in giving people, including the elderly, essential pain relief and support towards the end of their lives. The death rate was observed to be higher in this clinic than two similar palliative care clinics $(10 \%-37 \%)$ in other districts in Kerala. $[29,30]$. The higher death rate probably reflects the active follow up mechanism and hence the enhanced death reporting.

Studies have reported that utilization of palliative care is determined by socio-economic status. Patients with a low socio economic status were more likely to access home based palliative care services and patients with higher socioeconomic status tended to prefer institutional specialty care [30, 42]. We did not find any difference in utilization between patients classified as poor or wealthy. This might reflect the level of acceptability and performance of the palliative care programme in Manjeri as well as the specifics of the context in Kerala.

Patients opt out of palliative care due to two reasons; either when they get cured and no longer require the support of palliative care team or when they prefer other methods of care [30]. The opting out has to be discussed in the context of the service provision ie whether it is provided free or charged. In settings where palliative care is mostly a paid service, socio-economic status and availability of informal care provider determine use of palliative care [42]. In Kerala, home care visits by doctors and nurses, medicines and consumables are provided free of cost to patients [30]. The reason for patients opting out of home based palliative care in another setting in Kerala has been reported to be lack of social support [30]. The rate of opting out from Manjeri clinic was lower compared to another clinic in the neighbouring district. ( $7 \%$ vs $12 \%$ in Thrissur) (29). Several other predictors of the use of home-based palliative care service are also reported in literature [30].

We found out that those aged less than 60 years, those with serious mental illness and those who received few doctor visits were more likely to opt out of care.

Those who opt out of care are younger and this is consistent with literature [29]. The elderly was the predominant beneficiary group of this palliative care programme. We speculate that the elderly patients might 
Table 3 Factors associated with opting out of palliative care among newly registered patients in the Manjeri Palliative Care Unit, Kerala during 2013-2015

\begin{tabular}{|c|c|c|c|c|c|c|}
\hline Variables & $\mathrm{N}$ & Opted out of care N (\%) & Unadjusted RR(95\%Cl) & $p$-value & Adjusted RR(95\%Cl) & $p$-value \\
\hline Age group ${ }^{a}$ & & & & $<0.001$ & & \\
\hline$\leq 60$ & 165 & $27(16)$ & $5.1(2.7-9.8)$ & & $3.7(1.9-7.4)$ & $<0.001$ \\
\hline$>60$ years & 375 & 12(3) & ref & & ref & \\
\hline $\operatorname{Sex}^{\mathrm{a}}$ & & & & 0.3 & & \\
\hline Male & 265 & $22(8)$ & $1.4(0.8-2.6)$ & & - & - \\
\hline Female & 280 & $17(6)$ & ref & & - & - \\
\hline Socio-economic status ${ }^{\mathrm{a}, \mathrm{b}}$ & & & & 0.25 & & \\
\hline Poor & 260 & $21(8)$ & $1.9(0.6-5.5)$ & & - & - \\
\hline Middle class/Wealthy & 244 & $16(7)$ & ref & & - & - \\
\hline Type of care-giver & & & & 0.09 & & \\
\hline Spouse & 168 & $13(8)$ & $0.9(0.5-1.7)$ & & - & - \\
\hline Other & 372 & $27(7)$ & ref & & - & - \\
\hline Primary clinical & & & & $<0.001$ & & \\
\hline \multicolumn{7}{|l|}{ diagnosis } \\
\hline Cancer & 151 & $11(7)$ & $0.9(0.5-1.9)$ & & $0.7(0.4-1.4)$ & 0.3 \\
\hline Serious Mental IIIness & 33 & $9(27)$ & $3.7(1.8-7.5)$ & & $1.9(1.3-3.8)$ & 0.01 \\
\hline Other & 244 & 18(8) & ref & & ref & \\
\hline CVA & 123 & $2(2)$ & $0.2(0.05-0.9)$ & & $0.3(0.08-0.9)$ & 0.04 \\
\hline $\begin{array}{l}\text { Number of home visits in first year of } \\
\text { enrollment by doctor }\end{array}$ & & & & 0.03 & & \\
\hline$\leq 1$ & 293 & $31(10)$ & $2.9(1.4-6.1)$ & & $2.4(1.2-6.0)$ & 0.03 \\
\hline$>1$ & 247 & $9(4)$ & ref & & ref & \\
\hline $\begin{array}{l}\text { Number of home visits the first year of } \\
\text { enrollment by nurse }\end{array}$ & & & & 0.019 & & \\
\hline$\leq 5$ & 283 & $28(4)$ & $2.1(1.1-4.1)$ & & $1.2(0.7-2.7)$ & 0.1 \\
\hline$>5$ & 257 & $12(2)$ & ref & & ref & \\
\hline
\end{tabular}

CVA Cardiovascular Accident, RR Relative Risk, Cl Confidence Interval

adata missing

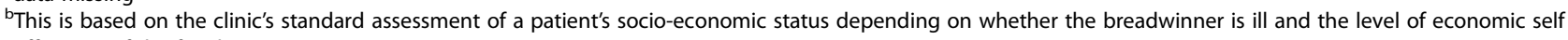
sufficiency of the family

SOther include children, daughters-in-law, parents, sisters-in-law and hired caregivers

Figures in bold font indicate significant $p$ value $(<0.05)$

have more severe disease compared to their younger counterparts, rendering them dependent on palliative care services.

The two morbidities which predicted patient's decision to continue in care were CVA and mental illness. Patients with CVA continued to stay in palliative care longer, compared to patients with other conditions. Patients with CVA formed the predominant group cared for in a similar setting [29].

We also found that those with Serious Mental Illness (SMI) opted out of palliative care. This is an important finding as this category receives predominantly clinic based care and fewer home visits from doctors and nurses. The service for mentally ill patients is mainly through the weekly psychiatry consultation in the clinic. Patient's family is reminded of the follow up through telephone by the palliative care nurse. The reason for this group opting out of palliative care needs to be explored further.

Another predictor for opting out of care was receiving fewer visits from palliative care physicians. Physician visits are restricted to severe cases as charted out by the nurse. Therefore, we speculate that cases which received fewer visits from the physician are the ones which are less severe and therefore more likely to opt out of care.

Although existing evidence in literature states that males tend to use palliative care services lesser, we did not see this differentiation in this study [30]. Presence of a caregiver is said to predict utilization of palliative care. While some studies say that those who have unpaid caregivers tend to use palliative care less, others report that the use is enhanced when the patient has a care 
giver as they have someone to advocate on their behalf [43-46]. In our setting the presence of a caregiver especially spouse was not a predictor of continuing in palliative care.

One of the strengths of the study was that a large cohort of patients under palliative care was studied over a period of two decades.

There were also several limitations to this study. Firstly, we did not explore the quality of life of patients at enrolment and thereafter to quantify the impact of the programme on their lives. Secondly, the study did not explore the interim illnesses and immediate causes of death which would inform the specific professional skills needed for improving end of life care. Thirdly, the study also did not explore the reasons for opting out of home care. Fourthly, a long 20-year period of observation in this study might have seen changes in policy and practice related to palliative care. However, we have tried to take into account these changes to explain the patient enrolment and diagnosis pattern over the same period.

\section{Conclusion}

This study has shown the changing dynamics of a palliative care programme in the Indian state of Kerala over a 20 -year period, and highlights the need for similar programmes to remain flexible and able to adapt their services to a changing population in response to a growing global burden of NCDs. The variety of patients with different chronic conditions exemplifies the diverse range of clinical and psycho-social support skills required when caring for a cohort such as this one. The low rates of opting out of home care indicate the strengths of this care model. Future qualitative research is required to further understand the strengths and weaknesses of this home based care model and the experiences of the providers and caregivers.

\section{Abbreviations}

CBO: Community Based Organisation; CVA: Cerebrovascular Accident; LSGIs: Local Self Government Institutions; NCDs: Non-Communicable Diseases; SMI: Serious mental illness

\section{Acknowledgements}

This research was conducted through the Structured Operational Research and Training Initiative (SORT IT), a global partnership led by the Special Programme for Research and Training in Tropical Diseases at the World Health Organization (WHO/TDR). The model is based on a course developed jointly by the International Union Against Tuberculosis and Lung Disease (The Union) and Medécins sans Frontières (MSF/Doctors Without Borders). The specific SORT IT programme which resulted in this publication was jointly developed and implemented by: The Union South-East Asia Office, New Delhi, India; the Centre for Operational Research, The Union, Paris, France; the Operational Research Unit (LUXOR), MSF Brussels Operational Center, Luxembourg; Department of Preventive and Social Medicine, Jawaharlal Institute of Postgraduate Medical Education and Research, Puducherry, India; Department of Community Medicine, Pondicherry Institute of Medical Sciences, Puducherry, India; Department of Community Medicine, Sri ManakulaVinayagar Medical College and Hospital, Puducherry, India; Department of Community Medicine, Velammal Medical College Hospital and Research Institute, Madurai, Tamil Nadu; NarotamSekhsaria Foundation, Mumbai, India; and National Institute for Research in Tuberculosis, Chennai,
India. We express our gratitude to Mr. Shibu, Coordinator, Manjeri Pain \& Palliative Care clinic for helping us to fetch the registers and records. A special thanks to Divya Philip for helping with data entry.

\section{Funding}

The training programme was funded by the Department for International Development (DFID), UK and La Foundation Veuve Emile Metz-Tesch (Luxembourg). The funders had no role in study design, data collection and analysis, decision to publish, or preparation of the manuscript.

\section{Availability of data and materials}

Data is available with the corresponding author (RRP) and will be available on request at the following e-mail: rekharachel@gmail.com.

\section{Authors' contributions}

RRP: Participated in the design of the study, performed study procedures, collection and entry of data, analysis of data, and was responsible for interpretation of data, drafting and editing of the manuscript. SP: Participated in the conception and design of the study, analysis of data, and took part in revising and editing of the manuscript. JP: Participated in the design of the study, analysis and interpretation of data, as well as drafting and revising the manuscript AM: Participated in the conception and design of the study, facilitated data collection and helped with editing of the manuscript. EV: Participated in the design of the study, analysis and interpretation of data, and took part in drafting and editing of the manuscript. All authors have read and approved the final manuscript.

\section{Ethics approval and consent to participate}

Since permissions were not possible from those individuals whose past records were accessed for the study we could not take informed consent from the patients. The study protocol was presented and discussed with the managing committee of Manjeri Pain and Palliative clinic. The committee gave permission to conduct the study (Ref No.R1/16-17)). The Institutional Ethics Committee of Government Medical College Manjeri also reviewed the study protocol and agreed that since only secondary data from records was being used for this research, permission from the authorities of the Manjeri pain and palliative care clinic would be enough (IEC No.01/EC03/2017/ GMCM). Data confidentiality was strictly maintained. Only the study investigators had access to the data collected. Names and other personal identifiers were not collected. Hardcopies were kept in locked cabinets and softcopies in password protected computers. The Ethics Advisory Group of the International Union Against Tuberculosis and Lung Disease, Paris, France also gave ethical approval for conducting the study (EAG number: 97/16).

\section{Consent for publication}

Not applicable

\section{Competing interests}

The authors declare that they have no competing interests.

\section{Publisher's Note}

Springer Nature remains neutral with regard to jurisdictional claims in published maps and institutional affiliations.

\section{Author details \\ 'Department of Community Medicine, Government T.D Medical College, Alappuzha, Kerala, India. ${ }^{2}$ International Union Against Tuberculosis and Lung Disease, The Union South East Asia Office, New Delhi, India. ${ }^{3}$ Malappuram Initiative in Palliative Care, Malappuram, Kerala, India. ${ }^{4}$ Medical Department, Médecins Sans Frontières, Brussels, Belgium. ${ }^{5}$ Division of Social and Behavioural Sciences, School of Public Health and Family Medicine, University of Cape Town, Cape Town, South Africa.}

Received: 17 July 2017 Accepted: 25 January 2018

Published online: 14 February 2018

\section{References}

1. Murray CJ, Lopez AD. Mortality by cause for eight regions of the world: global burden of disease study. Lancet. 1997;349:1269-76.

2. World Health Organization. WHO: Global Atlas of Palliative care at the End of Life www.who.int/nmh/Global_Atlas_of_Palliative_Care.pdf. Accessed 21 June 2017. 
3. The World Bank. GNI per Capita, Atlas method. The World Bank Group; 2017. https://data.worldbank.org/indicator/NY.GNP.PCAP.CD. Accessed 29 Dec 2017.

4. International Agency for Research on Cancer (IARC) and World Health Organization. GLOBOCAN 2012: Estimated Cancer Incidence, Mortality and Prevalence Worldwide in 2012. http://globocan.iarc.fr/Pages/fact_sheets_ cancer.aspx. Accessed 29 Dec 2017.

5. Bleumink GS, Knetsch AM, Sturkenboom MC, Straus SM, Hofman A, Deckers JW, et al. Quantifying the heart failure epidemic: prevalence, incidence rate, lifetime risk and prognosis of heart failure the Rotterdam study. Eur Heart J. 2004:25:1614-9.

6. Halbert RJ, Natoli JL, Gano A, Badamgarav E, Buist AS, Mannino DM. Global burden of COPD: systematic review and meta-analysis. Eur Respir J. 2006;28: 523-32

7. Lynch T, Connor S, Clark D. Mapping levels of palliative care development: a global update. J Pain Symptom Manag. 2013;45:1094-106.

8. Smith S, Brick A, O'Hara S, Normand C. Evidence on the cost and costeffectiveness of palliative care: a literature review. Palliat Med. 2014;28:130-50.

9. Luckett T, Phillips J, Agar M, Virdun C, Green A, Davidson PM. Elements of effective palliative care models: a rapid review. BMC Health Serv Res. 2014;14:136.

10. Finlay IG, Higginson IJ, Goodwin DM, Cook AM, Edwards AG, Hood K, Douglas HR, Normand CE. Palliative care in hospital, hospice, at home: results from a systematic review. Ann Oncol. 2002;13(Suppl 4):257-64.

11. European Association for Palliative Care (EAPC). White paper on standards and norms for hospice and palliative care in Europe: recommendations from the European Association for Palliative Care. Eur J Palliat Care. 2009;16:278-89.

12. Centeno C, Lynch T, Donea O, Rocafort J, Clark D. EAPC atlas of palliative Care in Europe 2013. Milan: EAPC Press; 2013. http://www.pavi.dk/Files/ EAPC\%20Atlas\%20of\%20Pallaitive\%20Care\%20in\%20Europe\%202013\% 20webudgave.pdf. Accessed 30 Dec 2017

13. Froggatt KA, Reitinger E, Heimerl K, Hockley J, Brazil K, Kunz R et al. Palliative Care in Long-Term Care Settings for Older People: EAPC Taskforce 2010-2012. In: European Association of Palliative Care. 2013. http://www. eapcnet.eu/Portals/0/Organization/Long\%20term\%20care\%20settings/ FinalReportLongTermCareSettings_2013.pdf. Accessed 30 Dec 2017.

14. Inbadas H, Carrasco JM, Gillies M, Clark D. The level of provision of specialist palliative care services in Scotland: an international benchmarking study. BMJ Support Palliat Care. 2017. https://doi.org/10.1136/bmjspcare-2016001301. [Epub ahead of print]

15. Morrison RS. Models of palliative care delivery in the United States. Curr Opin Support Palliat Care. 2013;7(2):201-6.

16. Rabow MW, Dibble SL, Pantilat SZ, McPhee SJ. The comprehensive care team: a controlled trial of outpatient palliative medicine consultation. Arch Intern Med. 2004;164:83-91.

17. Sudore RL, Schickedanz AD, Landefeld CS, Williams BA, Lindquist K, Pantilat SZ, et al. Engagement in multiple steps of the advance care planning process: a descriptive study of diverse older adults. J Am Geriatr Soc. 2008;56:1006-13.

18. Teno JM. Now is the time to embrace nursing homes as a place of care for dying persons. J Palliat Med. 2003;6:293-6.

19. Hall S, Kolliakou A, Petkova H, Froggatt K, Higginson IJ. Interventions for improving palliative Care for Older People Living in nursing care homes. Cochrane Database Syst Rev. 2011;16(3):CD007132.

20. Harding R, Higginson IJ. Inclusion of end-of-life care in the global health agenda. Lancet Glob Health. 2014;2:375-6.

21. McDermott E, Selman L, Wright M, Clark D. Hospice and palliative care development in India: a multimethod review of services and experiences. J Pain Symptom Manag. 2008;35:583-93.

22. Kumar S. Models of delivering palliative and end-of-life care in India. Curr Opin Support Palliat Care. 2013;7:216-22.

23. Vijayaram S. India: status of cancer pain and palliative care. J Pain Symptom Manag. 1993;8:421-2.

24. Rajagopal MR. The challenges of palliative care in India. Natl Med J India 2001;14:65-7.

25. Singh T, Harding R. Palliative care in South Asia: a systematic review of the evidence for care models, interventions, and outcomes. BMC Res Notes. 2015:8:172.

26. Kumar SK. Kerala, India: a regional community-based palliative care model. J Pain Symptom Manag. 2007;33:623-7.

27. Kumar S, Numpeli M. Neighborhood network in palliative care. Indian J Palliat Care. 2005;11:6-9.

28. Paleri AK. Showing the way forward: pain and palliative care policy of the government of Kerala. Indian J Palliat Care. 2008;14:51-4.
29. Thayyil J, Cherumanalil JM. Assessment of status of patients receiving palliative home care and services provided in a rural area-kerala, India. Indian J Palliat Care. 2012;18(3):213-8.

30. Unni K, Edasseri D. A prospective survey of patient drop-outs in a palliative care setting. Indian J Palliat Care. 2012;18:27-30.

31. 2011 Census Data. Office of the Registrar General \& Census Commissioner, India. http://www.censusindia.gov.in/2011-Common/CensusData2011.html. Accessed 28 June 2017.

32. Government of Kerala. Human Development Report 2005. Trivandrum: State Planning Board; 2005. http://www.planningcommission.nic.in/kerala05.2005. Accessed 21 June 2017.

33. Paleri A, Numpeli M. The evolution of palliative care programmes in North Kerala. Indian J Palliat Care. 2005;11:15.

34. Marcucci FC, Cabrera MA, Perilla AB, Brun MM, de Barros EM, Martins VM, et al. Identification and characteristics of patients with palliative care needs in Brazilian primary care. BMC Palliat Care. 2016;15:51.

35. Santha S. Impact of pain and palliative care services on patients. Indian J Palliat Care. 2011;17(1):24-32.

36. World Health Organization. Global Status Report on Non Communicable Disease 2014. http://apps.who.int/iris/bitstream/10665/148114/1/ 9789241564854_eng.pdf. Accessed 29 Dec 2017.

37. Ministry of Social Justice, Government of India: National Policy for Senior Citizen 2011. http://socialjustice.nic.in/writereaddata/UploadFile/dnpsc.pdf. Accessed 29 Dec 2017

38. Sharma N, Chakrabarti S, Grover S. Gender differences in caregiving among family - caregivers of people with mental illnesses. World J Psychiatr. 2016;6:717.

39. Papastavrou E, Tsangari H, Kalokerinou A, Papacostas SS, Sourtzi P. Gender issues in caring for demented relatives. Health Sci J. 2009;3(1):41-53.

40. Tang B, Harary E, Kurzman R, Mould-Quevedo JF, Pan S, Yang J, et al. Clinical characterization and caregiver burden of dementia in China. Value Health Reg Issues. 2013;2(1):118-26.

41. World Health Organisation. WHO. Sixty-seventh World Health Assembly. Resolutions and Decisions.19-24 May 2014. Geneva: WHO; 2014.

42. Cai J, Guerriere DN, Zhao H, Coyte PC. Socioeconomic Differences in and Predictors of Home-Based Palliative Care Health Service Use in Ontario, Canada. Int J Environ Res Public Health. 2017;14(7)802. https://www.ncbi. nlm.nih.gov/pmc/articles/PMC5551240/

43. Grande GE, Farquhar MC, Barclay SI, Todd CJ. The influence of patient and carer age in access to palliative care services. Age Ageing. 2006; 35(3):267-73.

44. Hinton J. Which patients with terminal cancer are admitted from home care? Palliat Med. 1994;8(3):197-210.

45. Aoun S, Kristjanson L, Currow D, Skett K, Oldham L, Yates P. Terminally-ill people living alone without a caregiver: an Australian national scoping study of palliative care needs. Palliat Med. 2007;21(1):29-34

46. Addington-Hall J, Altmann D. Which terminally ill cancer patients in the United Kingdom receive care from community specialist palliative care nurses? J Adv Nurs. 2000;32(4):799-806. 